\title{
Fine mapping of barley locus Rps6 conferring resistance to wheat stripe rust
}

\author{
Kun $\mathrm{Li}^{1,2} \cdot$ Joshua Hegarty $^{2} \cdot$ Chaozhong Zhang ${ }^{1} \cdot$ Anmin Wan $^{3} \cdot$ Jiajie Wu $^{1} \cdot$ \\ Gina Brown Guedira ${ }^{4} \cdot$ Xianming Chen $^{3,5} \cdot$ María Muñoz-Amatriaín $^{6} \cdot$ Daolin $^{\mathrm{Fu}^{1}}{ }^{1}$ \\ Jorge Dubcovsky ${ }^{2,7}$
}

Received: 10 August 2015 / Accepted: 22 December 2015 / Published online: 13 February 2016

(c) The Author(s) 2016. This article is published with open access at Springerlink.com

\begin{abstract}
Key message Barley resistance to wheat stripe rust has remained effective for along time and, therefore, the genes underlying this resistance can be a valuable tool toengineer durable resistance in wheat.

Abstract Wheat stripe rust, caused by Puccinia striiformis f. sp. tritici (Pst), is a major disease of wheat that is causing large economic losses in many wheat-growing regions of the world. Deployment of Pst resistance genes has been an effective strategy for controlling this pathogen, but many of
\end{abstract}

Communicated by K. Smith.

D. Fu and J. Dubcovsky contributed equally to this work.

Daolin Fu

dlfu@sdau.edu.cn

Jorge Dubcovsky

jdubcovsky@ucdavis.edu

1 State Key Laboratory of Crop Biology, Shandong Key Laboratory of Crop Biology, Shandong Agricultural University, Tai' an 271018, Shandong, China

2 Department of Plant Sciences, University of California, Davis, CA 95616, USA

3 Department of Plant Pathology, Washington State University, Pullman, WA 99164, USA

4 USDA-ARS, Plant Science Research Unit, Department of Crop Science, North Carolina State University, Raleigh, NC 27695, USA

5 USDA-ARS, Wheat Genetics, Quality, Physiology, and Disease Research Unit, Pullman, WA 99164, USA

6 Department of Botany and Plant Sciences, University of California, Riverside, CA 92521, USA

7 Howard Hughes Medical Institute, Chevy Chase, MD 20815, USA these genes have been defeated by new $P$ st races. In contrast, genes providing resistance to this wheat pathogen in other grass species (nonhost resistance) have been more durable. Barley varieties (Hordeum vulgare ssp. vulgare) are predominately immune to wheat $P s t$, but we identified three accessions of wild barley (Hordeum vulgare ssp. spontaneum) that are susceptible to Pst. Using these accessions, we mapped a barley locus conferring resistance to $P s t$ on the distal region of chromosome arm 7HL and designated it as Rps6. The detection of the same locus in the cultivated barley 'Tamalpais' and in the Chinese barley 'Y12' by an allelism test suggests that Rps6 may be a frequent component of barley intermediate host resistance to $P s t$. Using a high-density mapping population ( $>10,000$ gametes) we precisely mapped Rps6 within a $0.14 \mathrm{cM}$ region $(\sim 500 \mathrm{~kb}$ contig) that is colinear to regions in Brachypodium ( $<94 \mathrm{~kb})$ and rice $(<9 \mathrm{~kb})$. Since no strong candidate gene was identified in these colinear regions, a dedicated positional cloning effort in barley will be required to identify Rps6. The identification of this and other barley genes conferring resistance to $P s t$ can contribute to our understanding of the mechanisms for durable resistance against this devastating wheat pathogen.

\section{Introduction}

Although more than 700 million tons of wheat (Triticum spp.) are produced per year worldwide (FAOSTAT 2013), further increases are required to support a growing human population. An important component of these increases in global production is the reduction of yield losses caused by various wheat pathogens. Wheat stripe rust, caused by Puccinia striiformis Westend. f. sp. tritici Erikss. (Pst), is one of the most destructive fungal diseases and is causing substantial yield and quality losses in many of the 
wheat-growing regions of the world (Chen et al. 2014; Wellings 2011). The appearance and spread of more virulent and aggressive Pst races since the beginning of this century has exacerbated the problem (Hovmøller et al. 2010; Wan and Chen 2014).

Fungicides can be applied to control Pst, but they generate additional costs and are potentially harmful to the environment. In contrast, the deployment of genetic sources of $P s t$ resistance is a reliable, environmentally friendly, and cost effective alternative to control Pst. However, the rapid evolution of novel Pst races has rendered many of these resistance genes ineffective (Chen et al. 2010), and has prompted the search for more durable sources of $P s t$ resistance.

A possible path to a more durable resistance is the identification and deployment of genes conferring resistance to Pst from plant species that are not normal hosts of this pathogen. This type of resistance is usually referred to as "nonhost resistance". Most pathogens cannot infect and cause disease on species that are different from their normal hosts, and this nonhost resistance is usually effective over long evolutionary periods (Bettgenhaeuser et al. 2014). However, the effectiveness and underlying genetic complexity of nonhost resistance is usually correlated with the taxonomic distance among the host and nonhost species (Bettgenhaeuser et al. 2014).

Studies of Arabidopsis resistance to the barley powdery mildew pathogen (Blumeria graminis f. sp. hordei, henceforth $B g h$ ) provide a good example of nonhost resistance against a pathogen from a very distantly related host species. Screenings of Arabidopsis mutants with increased $B g h$ penetration and haustoria formation ( $P E N$ genes) identified resistance genes PEN1, PEN2, and PEN3 (Collins et al. 2003; Lipka et al. 2005; Stein et al. 2006). However, even the Arabidopsis plants carrying all three mutations remained resistant to Bgh (Johansson et al. 2014). These results suggest that Arabidopsis nonhost resistance to pathogens from very distantly related species may have a complex genetic basis.

In contrast, barley resistance to Pst is not as effective as Arabidopsis resistance to $B g h$, and seems to have a simpler genetic basis. Races of $P s t$ usually do not infect barley, and those that infect barley (P. striiformis f. sp. hordei Erikss., henceforth $P s h$ ) are not often virulent on wheat. However, there are barley genotypes that can be infected by some Pst races and some wheat genotypes that can be infected by some Psh races (Chen et al. 1995; Kumar et al. 2012; Niks 1987; Pahalawatta and Chen 2005; Sui et al. 2010). In addition, two genetic studies have shown that barley resistance to Pst is determined mainly by few major genes (Pahalawatta and Chen 2005; Sui et al. 2010). These characteristics suggest that wheat and barley are in the earlier stages of development of nonhost resistance to different formae speciales of $P$. striiformis. The terms "intermediate host" and "intermediate non-host" resistance have been proposed to accommodate the continuum of rust infection outcomes observed in the transition from host to nonhost resistance (Bettgenhaeuser et al. 2014). Based on the characteristics described above, barley resistance to Pst can be classified as "intermediate host resistance".

Unfortunately, none of the genes underlying barley resistance to Pst has been identified so far, limiting our ability to test the effectiveness and durability of barley intermediate host resistance genes transferred to wheat. As a first step in the identification of barley genes conferring resistance to Pst, we developed a high-density map for a Pst resistance locus on chromosome $7 \mathrm{H}$ and explored the colinear regions in the rice and Brachypodium genomes for candidate genes. We also tested the presence of this resistance locus in the cultivated barley variety Tamalpais. The long-term objective of this project is to understand the genetic basis of barley intermediate host resistance to $P s t$ and to use that knowledge to generate wheat lines with more durable resistance to Pst.

\section{Materials and methods}

\section{Plant materials}

In 2010, 32 accessions of Hordeum vulgare ssp. spontaneum (K. Koch) Thell were screened in the field for resistance to Pst at the University of California, Davis (henceforth, UCD field). Two susceptible accessions (PI 264220 and PI 560559) collected in Turkey and two Pst resistant accessions (PI 466050 and PI 466186) collected in Syria (Table 1) were selected to develop two $\mathrm{F}_{2}$ populations segregating for $P s t$ resistance. The first population, generated from the cross PI $466050 \times$ PI 264220 , was designated as POP366 and included $127 \mathrm{~F}_{2}$ plants. The second population, generated from the cross PI $466186 \times$ PI 560559, was designated as POP371 and included $132 \mathrm{~F}_{2}$ plants.

Since the same locus was identified in both populations, we focused on POP366 to develop a high-density map. From this population, we selected $24 \mathrm{~F}_{2}$ plants heterozygous for the two markers flanking the major Pst resistance locus, allowed them to self-pollinate, and produced abundant $\mathrm{F}_{3}$ seeds. We genotyped $5444 \mathrm{~F}_{3}$ plants $(10,888$ segregating chromosomes), identified 746 plants carrying recombination events between the flanking markers, and used them to generate a high-density map. Once the locus was mapped more precisely, we developed closer flanking markers and reduced the number of $\mathrm{F}_{3}$ plants carrying recombination events in the critical region to 129. Each of these $129 \mathrm{~F}_{3}$ plants was self-pollinated and the corresponding $\mathrm{F}_{4}$ families were evaluated for resistance to $P s t$ to infer the genotype of the parental $F_{3}$ plant. 
Table 1 Reaction of Hordeum vulgare ssp. spontaneum to Puccinia striiformis f. sp. tritici in the UCD field in 2010

\begin{tabular}{|c|c|c|}
\hline Accession no. & Origin & Pst reaction \\
\hline PI 236386 & Syria & Resistant \\
\hline PI 244772 & Pakistan & Resistant \\
\hline PI 245740 & Turkey & Resistant \\
\hline PI 264220 & Turkey & Susceptible \\
\hline PI 282583 & Israel & Resistant \\
\hline PI 282586 & Israel & Resistant \\
\hline PI 284757 & Israel & Resistant \\
\hline PI 293394 & Turkmenistan & Susceptible \\
\hline PI 293401 & Turkmenistan & Resistant \\
\hline PI 293402 & Turkmenistan & Resistant \\
\hline PI 293413 & Azerbaijan & Resistant \\
\hline PI 293414 & Azerbaijan & Resistant \\
\hline PI 296803 & Israel & Resistant \\
\hline PI 296814 & Israel & Resistant \\
\hline PI 405294 & Israel & Resistant \\
\hline PI 405295 & Israel & Resistant \\
\hline PI 405304 & Israel & Resistant \\
\hline PI 405346 & Israel & Resistant \\
\hline PI 466020 & Syria & Resistant \\
\hline PI 466033 & Syria & Resistant \\
\hline PI 466039 & Syria & Resistant \\
\hline PI 466049 & Syria & Resistant \\
\hline PI 466050 & Syria & Resistant \\
\hline PI 466058 & Syria & Resistant \\
\hline PI 466062 & Syria & Resistant \\
\hline PI 466157 & Syria & Resistant \\
\hline PI 466186 & Syria & Resistant \\
\hline PI 466249 & Lebanon & Resistant \\
\hline PI 466253 & Lebanon & Resistant \\
\hline PI 466673 & Turkey & Resistant \\
\hline PI 560558 & Turkey & Resistant \\
\hline PI 560559 & Turkey & Susceptible \\
\hline
\end{tabular}

Since the Pst resistance locus identified in this study mapped to a similar chromosome location as the YrpstYl locus in Chinese barley line 'Y12' (Sui et al. 2010), we performed an allelism test to determine if they were the same or different genes. We reciprocally crossed the $P s t$ resistant lines Y12 and PI 466050 and generated an $\mathrm{F}_{2}$ population of 390 plants. This population was evaluated for susceptibility to Pst in 2015 at the UCD field facilities (Pst races used in the field inoculation are described below).

To determine if the locus identified in wild barley populations POP366 and POP371 was also present in cultivated barley (H. vulgare ssp. vulgare), we crossed the Pst resistant barley variety 'Tamalpais' (PI 645477, from California, used as male) with the Pst susceptible $H$. vulgare ssp. spontaneum accessions PI 264220 and PI 293394 (Table 1). The $F_{2}$ lines were advanced to $F_{5}$ by single-seed descent resulting in 161 lines that were tested for Pst resistance and were genotyped for markers linked to the resistance gene identified in POP366 and POP371.

\section{Tests of stripe rust reactions}

The parental lines of POP366 and POP371 were tested at Washington State University (WSU) for their responses to four North American Pst races (PSTv-14, PSTv-37, PSTv-40, and PSTv-51) and two North American Psh races (PSH-48 and PSH-58). The seedling tests for stripe rust resistance were performed twice and produced consistent results.

The $\mathrm{F}_{2}$ populations of POP366 and POP371 were initially tested for their responses to Pst in 2011 at the Shandong Agricultural University in Tai' an, China (SDAU). To validate the phenotype of the $\mathrm{F}_{2}$ plants, $\mathrm{F}_{3}$ progeny tests were conducted in the same field in 2012. For the Tamalpais-related populations, single-seed descent (SSD) $\mathrm{F}_{5}$ lines were tested at SDAU in 2014. Since no natural infections of Pst or Psh occur in this region, studies at SDAU used artificial Pst inoculations. Due to changes in spore availability, different $P s t$ races were used for the field inoculations in different years (2011: mixture of SY11, CYR31 and CYR32; 2012: CYR32, and 2014: mixture of CYR29, CYR31, CYR32 and CYR33). These have been predominant Pst races in China since the early 1990s, and their virulence profiles have been previously described (Wan et al. 2004; Chen et al. 2009). The $129 \mathrm{~F}_{3}$ plants carrying the critical recombination events were evaluated for resistance to Pst (some in growth chambers and others in the UCD field in 2014) and their $F_{4}$ progeny were evaluated in the UCD field in 2015. For the 2015 experiment in the UCD field, plants were inoculated with a mixture of Pst urediniospores collected in the UCD field in 2014 from Pst susceptible wheat plants. Analysis of 24 Pst samples from infected leaves collected at the UCD field in 2014 indicated the presence of the following races (followed by their frequency in parentheses): PSTv-4 (4.2\%), PSTv-11 (4.2\%), PSTv-15 (8.3\%), PSTv-17 (8.3\%), PSTv-37 (25.0 \%), PSTv-52 (41.7 \%), and PSTv-53 (8.3\%). No differences in the reactions of the susceptible and resistant barley parental lines were observed among the field studies in China and the USA. This is not an unexpected result as most of the cultivated barely accessions are resistant to all Pst races (Chen et al. 1995).

For the growth chamber tests, plants were inoculated at the two-leaf stage with urediniospores and kept in a dark dew chamber at $10{ }^{\circ} \mathrm{C}$ for $24 \mathrm{~h}$ and then transferred to a growth chamber with a diurnal temperature cycle that changed gradually from 4 to $20{ }^{\circ} \mathrm{C}$ with $16 \mathrm{~h}$ photoperiod 
(Chen et al. 2002; Pahalawatta and Chen 2005). Infection types (ITs) were recorded 20-22 days after inoculation using the McNeal's 0-9 scale reported before (Line and Qayoum 1992). To convert the Pst reactions into two genotypic classes for mapping purposes, IT scores from 0 to 4 were considered as resistant and IT scores from 6 to 9 as susceptible (plants with scores $=5$ were not used in the classification).

\section{Genotyping, linkage mapping and QTL analysis}

Genomic DNA was extracted from leaf tissues using the Sarkosyl method (Yuan et al. 2012), measured using ND-1000 spectrophotometry (Thermo Fisher Scientific, Wilmington, DE, USA), and normalized to $50 \mathrm{ng} \mathrm{Il}^{-1}$. A total of $93 \mathrm{~F}_{2}$ plants from POP371 and the two parental lines were genotyped using an Illumina VeraCode custom assay (del Blanco et al. 2014). This assay includes 384 single nucleotide polymorphisms (SNP) selected from the Illumina GoldenGate BOPA1 and BOPA2 assays for even coverage of the barley genome (Close et al. 2009). A genetic linkage map was created using the maximum likelihood mapping algorithm with the Kosambi function as implemented in JoinMap 4.0 (Kyazma B.V., Wageningen, Netherlands). The Windows QTL Cartographer V2.5 (Wang et al. 2012) was used to identify QTL for Pst resistance using composite interval mapping (window size: $10 \mathrm{cM}$; walk speed: $1 \mathrm{cM}$ ). Significance thresholds were established using 1000 permutation tests. QTL with a logarithm of odds (LOD) score of three or more were considered significant.

The degree of dominance was calculated using the formula: $D=\left(2 X_{2}-X_{1}-X_{3}\right) /\left(X_{1}-X_{3}\right)$ (Falconer 1964), where $X_{1}, X_{2}$ and $X_{3}$ are the infection types scores of the plants homozygous for the markers flanking the Rps6 resistant allele, the heterozygous, and the plants homozygous for the markers flanking the susceptible allele, respectively.

\section{Marker development}

To increase marker density in the target region, the parents of POP366 and POP371 were genotyped with the $9 \mathrm{~K}$ barley iSelect platform and PCR markers were designed for SNP previously mapped between flanking markers 11_10885 and 11_11012 (Comadran et al. 2012). In addition, we utilized colinear regions in Aegilops tauschii (Luo et al. 2013) (http://aegilops.wheat.ucdavis.edu/ATGSP/), Brachypodium, and rice to identify candidate genes within the region. We then used the barley draft genome sequence (International Barley Genome Sequencing Consortium 2012) and sequences from gene-bearing BACs (MuñozAmatriaín et al. 2015) to develop additional markers.
SNP and/or InDels were identified between the parents of POP366 and POP371 and PCR markers (e.g. CAP and dCAP) were developed. PCR primers, restriction enzymes and size of the expected products are described in Table 2. PCR products were separated in $6 \%$ non-denaturing acrylamide or $2 \%$ agarose gels.

To map barley loci (MLOC sequences from cultivar Morex) to barley FPC contigs, we blasted sequences of the mapped Morex loci against the Morex BAC end sequence database at IPK-Gatersleben. Only matches showing $100 \%$ identity over more than 500 bp were considered as correct matches. Barley genome $082214 \mathrm{v} 1$ was used to establish the approximate position of the Rps6 region on the $7 \mathrm{H}$ pseudomolecule (http://plants.ensembl.org/ Hordeum_vulgare/Info/Index).

\section{Expression of genes linked to marker development}

The expression of two genes completely linked to the resistance phenotype was studied in different tissues of the barley variety Golden Promise by RT-PCR. For gene MLOC_65262 we used forward primer 5'-TCGAGAGGCAGATCCAAGAT- $3^{\prime}$ and reverse primer $5^{\prime}$-TTTTGGCAAACCACTCTCCT-3 (expected size of RT-PCR product 137 bp). For MLOC_37425 we used forward primer $5^{\prime}$-ATCGGAGAAGGAGGAGAATATGG- $3^{\prime}$ and reverse primer 5'-TCATTTCAGAGGGTAAACAGCT-3' (expected size of RT-PCR product $546 \mathrm{bp}$ ). ACTIN (expected size of RT-PCR product $692 \mathrm{bp}$ ) was used as endogenous control using primers described before (Abu-Romman et al. 2011).

The RT-PCR conditions included an initial denaturation step $\left(94{ }^{\circ} \mathrm{C} 5 \mathrm{~min}\right.$ ), followed by 40 cycles of denaturation $\left(94^{\circ} \mathrm{C}, 30 \mathrm{~s}\right)$, annealing $\left(58^{\circ} \mathrm{C}, 30 \mathrm{~s}\right)$ and extension $\left(72^{\circ} \mathrm{C}\right.$, $1 \mathrm{~min})$, and a final extension step $\left(72{ }^{\circ} \mathrm{C}, 10 \mathrm{~min}\right)$. RNA was extracted from the middle region of leaf blades and sheaths and from roots of Golden Promise barley plants at the three-leaf stage, and from spikes before anthesis. Expression of these two genes was also explored in BARLEX (the Barley Draft Genome Explorer, Colmsee et al. 2015), where expression levels from RNAseq experiments in eight tissues from barley variety Morex are reported in a graphical form in FPKM (fragments per kb of exon per million reads mapped).

\section{Results}

\section{Wild barley accessions show differential responses to Pst races}

Three out of the 32 accessions of $H$. vulgare ssp. spontaneum that were evaluated in the UCD field in 2010 for Pst resistance, were found to be susceptible to Pst supporting 


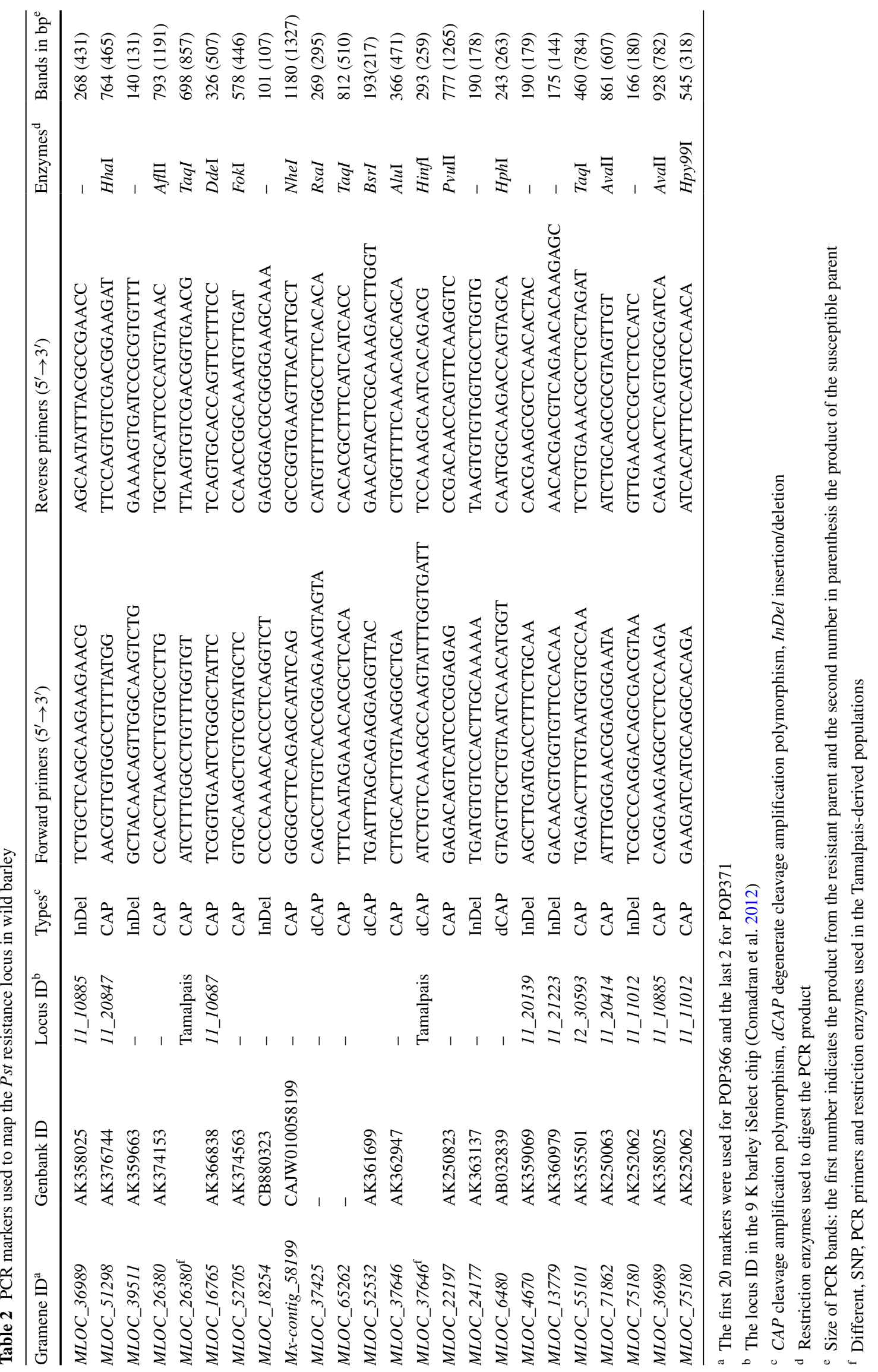


Table 3 Reaction of Hordeum vulgare ssp. spontaneum seedlings to $P$ st and $P$ sh races under controlled environments

\begin{tabular}{|c|c|c|c|c|c|c|}
\hline \multirow[t]{2}{*}{ Lines } & \multicolumn{4}{|l|}{ Pst races } & \multicolumn{2}{|c|}{ Psh races } \\
\hline & $\begin{array}{l}\text { PSTv-14 } \\
\text { (PST-127 }^{\text {PST-139) }} \\
\text { PST }^{\mathrm{a}} \\
2009^{\mathrm{b}}\end{array}$ & $\begin{array}{l}\text { PSTv-37 } \\
\text { (PST-100 } \\
\text { PST-102) } \\
2003\end{array}$ & $\begin{array}{l}\text { PSTv-40 } \\
\text { (PST-114 } \\
\text { PST-116) } \\
2004-2005\end{array}$ & $\begin{array}{l}\text { PSTv-51 (PST-114+ } \\
\text { PST-127) } \\
2004-2007\end{array}$ & $\begin{array}{l}\text { PSH-48 } \\
2011\end{array}$ & $\begin{array}{l}\text { PSH-58 } \\
2001\end{array}$ \\
\hline PI 466050 & 1 & 1 & 1 & 1 & $7-8$ & 8 \\
\hline PI 466186 & $1-4$ & $1-4$ & $1-4$ & 1 & $7-8$ & 8 \\
\hline PI 264220 & $5-8$ & 8 & $7-8$ & 8 & 8 & $7-8$ \\
\hline PI 560559 & $5-7$ & 7 & 7 & 6 & $7-8$ & 8 \\
\hline Avocet $S^{c}$ & 8 & 8 & 8 & 8 & 1 & 1 \\
\hline Steptoe $^{\mathrm{d}}$ & 1 & 1 & 1 & 1 & $7-8$ & 8 \\
\hline
\end{tabular}

a Names in parenthesis indicate similar races in the previous nomenclature system (Wan and Chen 2014). PSTV-51 is a new race that combines virulence previously observed in PST-114 and PST-127

${ }^{\mathrm{b}}$ First year the original races were identified

c Wheat control susceptible to Pst

d Barley control susceptible to Psh abundant sporulation and the rest were resistant and did not support sporulation (Table 1). The seedling responses to Pst under controlled environmental conditions of the four $H$. vulgare ssp. spontaneum accessions selected as parental lines were consistent with the results observed in the field (Table 3). All four $H$. vulgare ssp. spontaneum accessions were highly susceptible to $P$ sh races PSH-48 and PSH-58 but differed in their susceptibility to the four tested races of Pst (Table 3). Accessions PI 466050 and PI 466186 exhibited resistant responses to all Pst races (IT, 0-4) whereas accessions PI 264220 and PI 560559 were susceptible (IT, 6-8) to the same races. The cultivated barley control 'Steptoe' was susceptible to both $P$ sh races and resistant to all four Pst races, whereas the wheat control 'Avocet S' was susceptible to all $P s t$ races and resistant to both $P$ sh races (Table 3).

The adult plant $P s t$ resistance reactions observed in the field trials in China and USA were consistent with the resistance responses observed for the same lines at the seedling tests under controlled environmental conditions. In all field trials, PI 466050 and PI 466186 were resistant to the field races of Pst (chlorotic/necrotic responses with no or slight sporulation, IT scores $=1-4$ ), whereas PI 264220 and PI 560559 were susceptible (abundant sporulation, IT scores $=7-8)$.

\section{Identification of a major Pst resistance locus on chromosome arm $7 \mathrm{HL}$}

In the first evaluation of POP366 and POP371 at SDAU in 2011 both populations showed segregation for responses to Pst, with IT scores ranging from 1 to 7 . Seeds were obtained from each $\mathrm{F}_{2}$ plant and progeny tests were performed for all $\mathrm{F}_{3}$ families in 2012 in the same location.
Among the $127 \mathrm{~F}_{3}$ families analyzed from POP366, 35 were uniformly resistant to Pst, 58 showed segregation and 34 were uniformly susceptible, suggesting segregation for a single genetic locus $\left(\chi_{1: 2: 1}^{2}=0.97, P=0.62\right)$. Among the $131 \mathrm{~F}_{3}$ families analyzed from POP371, 33 were homozygous resistant to Pst, 67 showed segregation and 31 were homozygous susceptible, also suggesting segregation at a single genetic locus $\left(\chi_{1: 2: 1}^{2}=0.13, P=0.94\right)$.

To map this resistance locus, we genotyped $93 \mathrm{~F}_{2}$ plants from POP371 and the two parental lines using the 384-SNP Illumina VeraCode custom assay described in the "Materials and methods". We identified 71 polymorphic markers and were able to map 69 of them to 11 linkage groups with a cumulative map distance of $831.2 \mathrm{cM}$ (two SNPs remained ungrouped). Using a published genetic map of barley 9K iSelect chip (Comadran et al. 2012), we assigned the mapped markers to their known chromosome locations and generated an integrated genetic map including seven linkage groups (Fig. 1).

A QTL analysis of the Pst resistance scores obtained in the $\mathrm{F}_{2}$ plants in 2011 revealed a single significant QTL between markers 11_10885 and 11_11012 on the long arm of chromosome 7H. This QTL was associated with a LOD score of 25.8 and explained $30.5 \%$ of the phenotypic variation in $P s t$ resistance. No other QTL with a LOD score higher than three was identified, suggesting the presence of a single major Pst resistance locus segregating in POP371. However, we cannot rule out the possibility of additional QTL in regions not covered by this map.

We then developed PCR markers for 11_10885 and 11_11012 (Table 2), and used them to map the Pst resistance locus in the complete POP371 and POP366 populations. Using the $\mathrm{F}_{3}$ progeny test performed in 2012, we mapped Pst resistance as a simple Mendelian locus in 


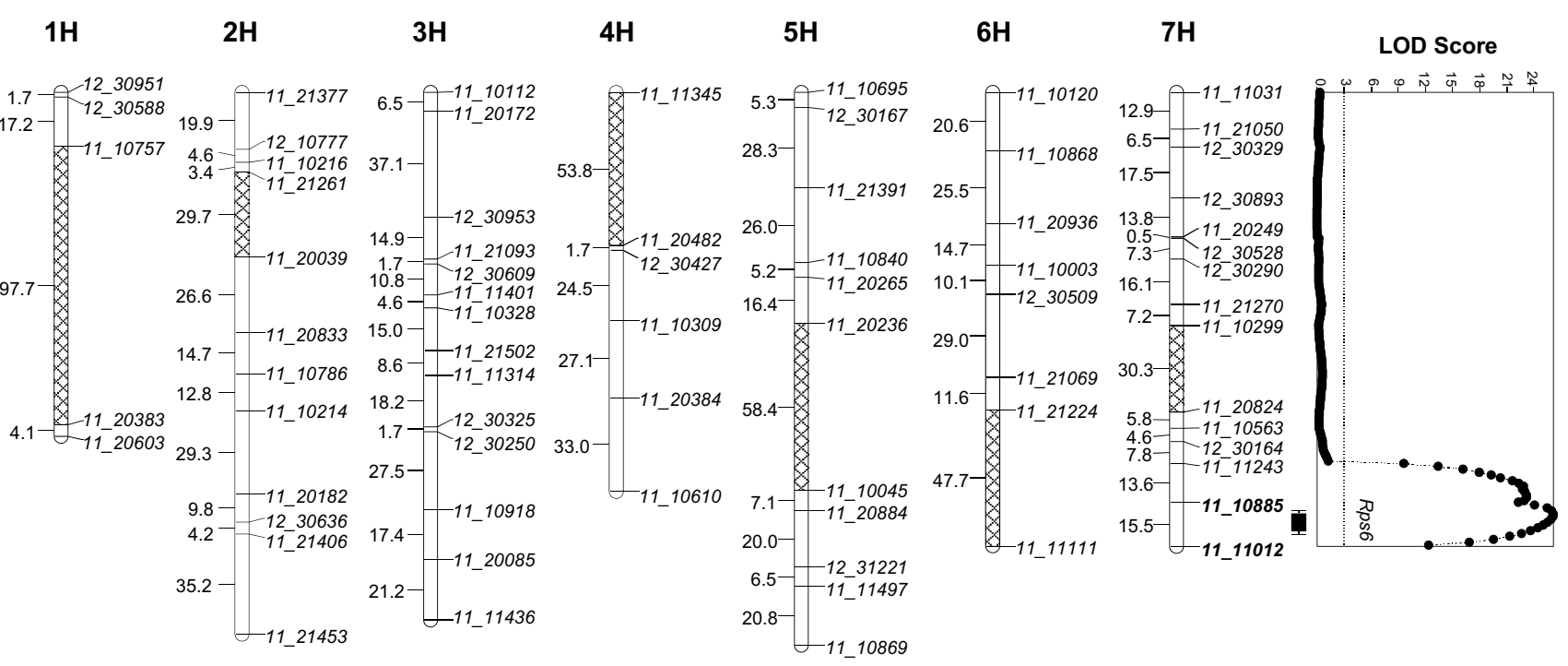

Fig. 1 Linkage groups and QTL for Puccinia striiformis f. sp. tritici (Pst) resistance in POP371. A total of 69 polymorphic SNP were initially mapped into 11 linkage groups that were integrated into the 7 barley chromosomes using information from a previous map (Comadran et al. 2012) and from barley genome assembly 082214v1. Cross- hatched regions indicate gaps in our linkage data inferred from the published data. QTL analysis identified a single significant QTL on the distal region of chromosome 7HL that is presented to the right of that chromosome

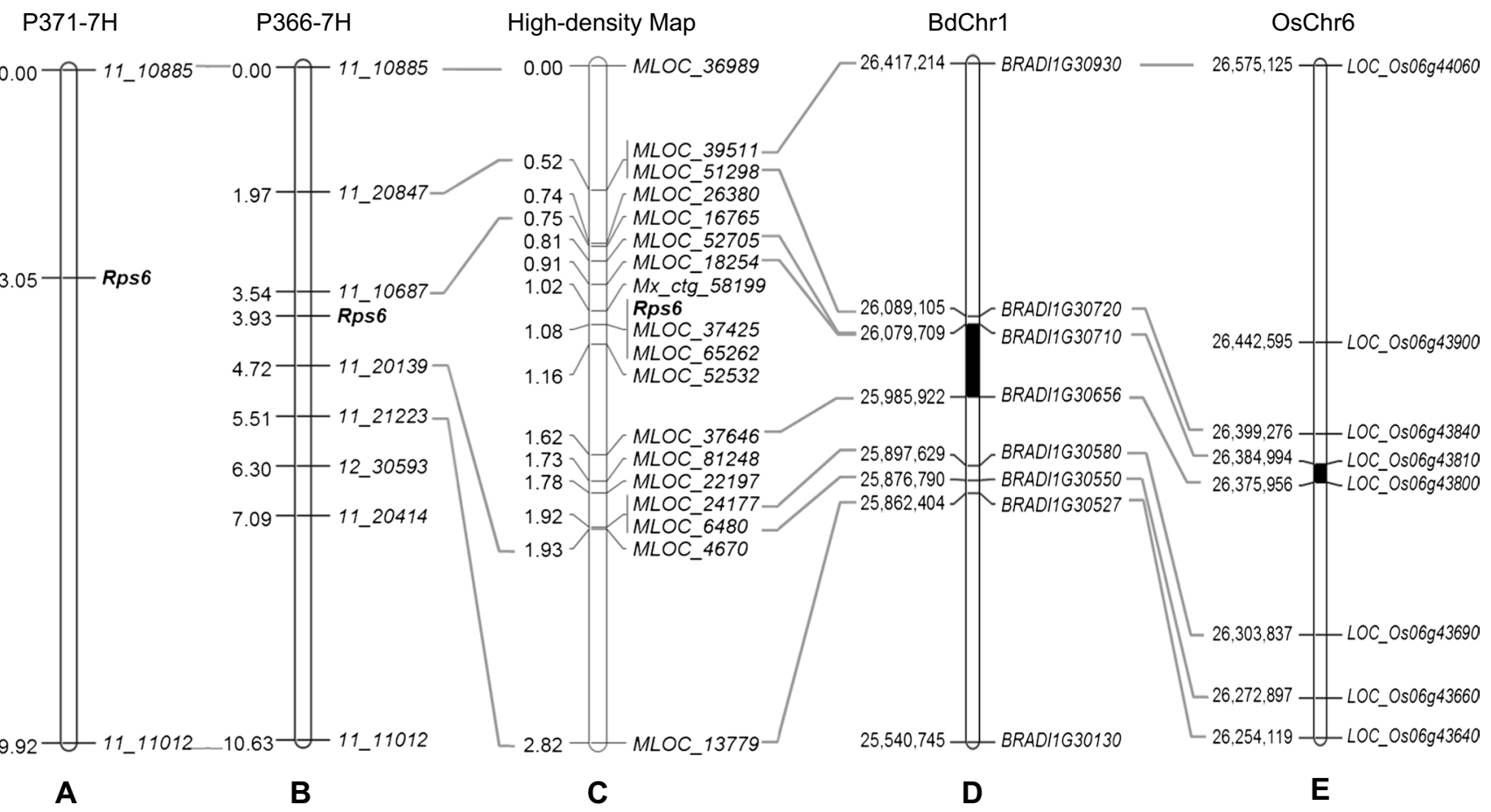

Fig. 2 Genetic maps of the Rps 6 region and their colinearity with Brachypodium and rice sequenced genomes. a Barley genetic map based on POP371 (cM). b Barley genetic map based on POP366. c Barley high-density map based on 10,888 gametes. d Colinear region in Brachypodium chromosome 1 (pseudomolecule in bp). e Colinear region in rice chromosome 6 (pseudomolecule in bp). Black regions in $\mathbf{d}$ and $\mathbf{e}$ indicate the Rps 6 candidate region. MLOC numbers are gene identification numbers in Ensembl Plants 
a similar location in both populations (Fig. 2a, b). These results suggest that resistance to Pst in POP366 and POP371 is determined by a major locus that maps 3.0 $3.9 \mathrm{cM}$ distal to marker $11 \_10885$ and $6.7-6.9 \mathrm{cM}$ proximal to marker 11_11012 (Fig. 2a, b). Following barley rules for resistance gene nomenclature, this locus has been assigned the formal name Rps6.

Using the complete $\mathrm{F}_{2}$ population POP371 we estimated the average IT for the plants homozygous for the markers flanking the resistant allele (average IT $=2.2$ ), for the heterozygous plants (average IT $=3.7$ ), and for the plants homozygous for the markers flanking the susceptible allele (average IT $=7$ ). The average IT score of the heterozygous plants was lower (more resistant) than the midpoint between the homozygous resistant and homozygous susceptible plants $(\mathrm{IT}=(2.2+7.0) / 2=4.6)$. The degree of dominance of the resistant allele was estimated to be $38 \%$ using the formula described in the "Materials and methods".

\section{Rps6 is allelic to YrpstY1}

A review of previous studies showed that barley Pst resistance gene YrpstYl from the Chinese barley line Y12 was mapped on a chromosome region similar to the one identified in this study for Rps6. YrpstYl was mapped $27 \mathrm{cM}$ from the most distal markers on chromosome arm 7HL (Sui et al. 2010) while Rps6 was mapped approximately $20 \mathrm{cM}$ from the most distal markers on the same chromosome arm: 7 cM from Rps6 to 11_11012 (Fig. 2a) plus $13 \mathrm{cM}$ from 11_11012 to 11_20170 (Barley, OPA 2011, Consensus http://wheat.pw.usda.gov/GG3/maps-short, Muñoz-Amatriaín et al. 2011).

To determine if Rps6 and YrpstYl are allelic we generated reciprocal crosses between resistant lines PI 466050 and Y12 (both carrying a single dominant Pst resistance gene), and evaluated the $F_{1}$ and $F_{2}$ plants derived from these crosses for resistance to Pst in the UCD field in 2015. PI 466050, Y12 and the two reciprocal $\mathrm{F}_{1}$ hybrids were resistant to Pst (IT: 0-2). The $260 \mathrm{~F}_{2}$ progeny from the cross PI $466050 \times \mathrm{Y} 12$ and the $130 \mathrm{~F}_{2}$ progeny from the cross Y12 × PI 466050 were all resistant to Pst (IT: 0-3), confirming allelism between Rps6 and YrpstY1. Therefore, the low-density map of YrpstY1 (Sui et al. 2010) should be considered the first map of Rps6.

\section{The Rps6 locus is also associated with Pst resistance in cultivated barley}

The previous allelism test suggested that the Rps6 locus identified in this study in $H$. vulgare ssp. spontaneum and the YrpstYl identified in $H$. vulgare cultivar Y12 (Sui et al. 2010) are likely alleles of the same gene. This result suggested that Rps6 is likely to be present in other $H$. vulgare cultivars.

To test this hypothesis we selected the barley cultivar 'Tamalpais' (PI 645477), which displays excellent resistance (IT scores 0-1) to wheat stripe rust in China and USA and crossed it with the susceptible wild barley accessions PI 264220 and PI 293394 (Table 1). Of the $161 \mathrm{~F}_{5}$ plants, 42 were susceptible to Pst races CYR29, CYR31, CYR32 and CYR33. Since $\mathrm{F}_{5}$ plants are $93.75 \%$ homozygous, the observed 3-1 segregation $\left(\chi_{3: 1}^{2}=0.10, P=0.75\right)$ is consistent with the hypothesis of segregation for two major resistance genes. We genotyped 20 susceptible and 21 plants with the highest levels of resistance from these two populations using markers MLOC_26380 (for the Tamalpais/PI 264220 population, Fig. 3a) and MLOC_37646 (for the Tamalpais/PI 293394 population, Fig. 3b). We found that all susceptible plants (and none of the resistant plants) were homozygous for the susceptible parent allele, confirming that Rps6 plays an important role in 'Tamalpais' resistance to Pst. As expected from the selection of the most resistant plants for genotyping, the proportion of plants homozygous for the resistant allele were higher than expected by chance (Fig. 3a, b).

\section{Rps6 maps to a $0.14 \mathrm{cM}$ interval between markers Morex contig_58199 (Mx_ctg_58199) and MLOC_52532}

First, we selected six SNP evenly distributed between markers 11_10885 and 11_11012 from the $9 \mathrm{k}$ iSelect array map (Comadran et al. 2012) (Table 2) and developed PCR markers. We then incorporated these markers in the low-density map from POP366 $\left(127 \mathrm{~F}_{3}\right.$ progenies, Fig. $\left.2 \mathrm{~b}\right)$ and reduced the Rps 6 candidate region to a $1.2 \mathrm{cM}$ interval between markers 11_10687 and 11_20139 (Fig. 2b).

To develop a high-density map we genotyped $5444 \mathrm{~F}_{3}$ plants and identified 746 plants with recombination events between Rps6 flanking markers $11 \_10885$ and 11_11012 (Fig. 2c). Among the selected plants, we focused on the 129 $\mathrm{F}_{3}$ plants that showed recombination events between the closest Rps6 markers 11_10687 and 11_20139. These recombinant chromosomes were in heterozygous state and segregated in the progeny tests for Pst resistance performed at the UCD field in 2015 ( $\mathrm{F}_{4}$ plants). Using this information we mapped the Rps6 locus $0.33 \mathrm{cM}$ distal to $11 \_10687$ (= MLOC_16765) and $0.85 \mathrm{cM}$ proximal to $11 \_20139$ (= MLOC_4670, Fig. 2c). These genetic distances were very similar to the ones obtained in the low-density map of POP366 (Fig. 2b).

To map the recombination events more precisely, we generated additional markers in the 11_10687-11_20139 interval using sequence information from barley (http://webblast. ipk-gatersleben.de/barley/viroblast.php), and the colinear regions in the genomes of $A$. tauschii (http://avena.pw.usda. gov/wheatD) (Luo et al. 2013), Brachypodium (http://www. 
Tamalpais / PI 264220 (MLOC_26380)
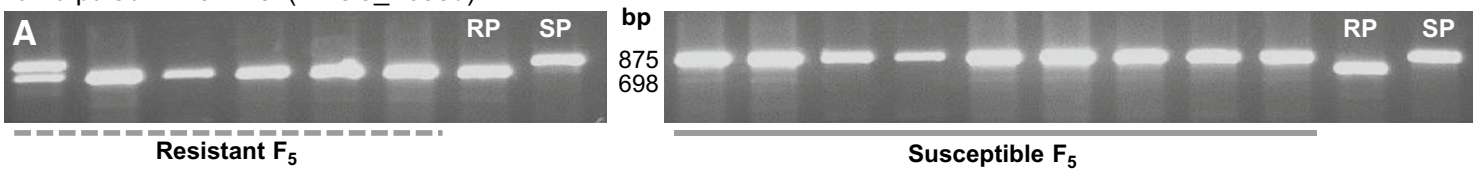

Tamalpais / PI 293394 (MLOC_37646)
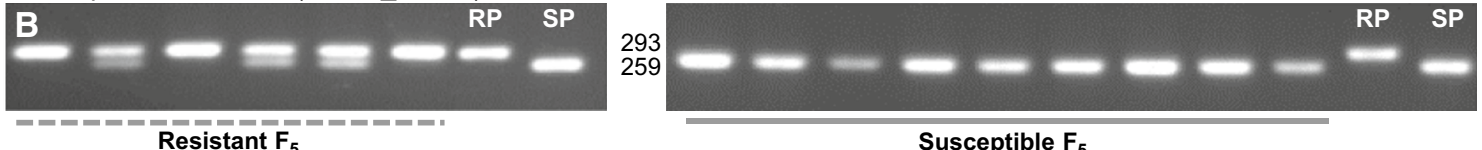

Fig. 3 Genotypes of selected $F_{5}$ plants derived from crosses between $P s t$ resistant cultivated barley variety Tamalpais and $P s t$ susceptible wild barley accessions PI 264220 and PI 293394. a $\mathrm{F}_{5}$ plants from Tamalpais/PI 264220 genotyped with CAP marker MLOC_26380 digested with TaqI. b F 5 plants from Tamalpais/PI 293394 genotyped with distal marker MLOC_37646 digested with HinfI. RP = resistant

plantgdb.org/BdGDB) and rice (http://rice.plantbiology. msu.edu/cgi-bin/gbrowse/rice/) (Fig. 2c). Using these new markers and available recombination events we mapped Rps6 completely linked to markers MLOC_37425 and MLOC_65262, and within a $0.14 \mathrm{cM}$ region flanked in the distal side by $M x \_c t g \_58199(0.06 \mathrm{cM})$ and in the proximal side by MLOC_52532 (0.08 cM, Fig. 2c).

BLASTN searches of the sequences from the markers in the Rps6 region against the IPK-Gatersleben database of BAC end-sequences showed that markers $M x_{-}$ ctg_58199, MLOC_37425, MLOC_65262, MLOC_52532, and MLOC_37646 have perfect matches $(100 \%,>500 \mathrm{bp})$ to BACs located in the large FPC contig_320 (3.46 Mb). The order of the markers in the high-density map was colinear with the order of the corresponding BACs in FPC contig_320 (Fig. 4). The BACs with BAC end-sequences matching markers Mx_ctg_58199 (HVVMRXALLeA0155A06) and MLOC_52532 (HVVMRXALLHB00096P12) delimit a region of $501 \mathrm{~kb}$ in FPC contig_320.

\section{The Rps6 target region in barley is colinear with regions in the Brachypodium and rice genomes}

Since the complete sequence of FPC ctg_320 is still not available, we explored the colinear regions from other sequenced genomes to search for potential candidate genes. Of the eighteen markers incorporated on the barley high-density genetic map (Fig. 2c), eight are perfectly colinear with Brachypodium chromosome 1 and rice chromosome 6 (Fig. 2c-e). These data indicate good conservation of gene order in this region among barley, Brachypodium, and rice genomes.

Since no orthologs were found in the Brachypodium and rice colinear regions for the closest barley markers flanking Rps6 (Mx_ctg_58199 and MLOC_52532), we used the next parent (Tamalpais), and SP = susceptible parent (PI 264220 in a and PI 293394 in b). The size of the amplification products in bp is indicated between the left and right panels. Markers used for these two loci are based on different SNP than the ones used in the wild barley populations, and their specific primers are listed in Table 2

adjacent markers MLOC_18254 and MLOC_37646 (Fig. 2c) to determine the colinear candidate region in these two model plant species. These two markers are located $0.7 \mathrm{cM}$ apart in the high-density map and their orthologs define a $93.8 \mathrm{~kb}$ in Brachypodium chromosome $1(25,985,922$ to $26,079,709)$ and a $9 \mathrm{~kb}$ region in rice chromosome $6(26,375,956-26,384,994)$.

The colinear region in Brachypodium contains five genes between the two flanking markers (Fig. 2d; Table 4) (http:// www.plantgdb.org/BdGDB/). Three of these five genes are predicted proteins of unknown function, while the other two are annotated as a Cytochrome P450 71D8-like (Bradilg30700) and a predicted Zinc finger MYM-type protein 1-like (Bradilg30672). We were not able to find barley orthologs for any of these five Brachypodium genes in the $7 \mathrm{HL}$ target region. The colinear region in rice contained no additional genes between the rice orthologs of the barley flanking markers (LOC_OsO6g43800 and LOC_OsO6g43810, http://rice.plantbiology.msu.edu/cgi-bin/gbrowse/rice/).

Since no promising candidate genes were identified in the Brachypodium or rice colinear regions, we searched for additional candidate genes in the colinear regions in A. tauschii (http://aegilops.wheat.ucdavis.edu/ATGSP/blast.php). Six barley markers showed significant sequence identity with sequence flanking five SNPs spanning the region between 175.0 and $187.4 \mathrm{cM}$ on A. tauschii chromosome 7D, and good colinearity was detected between these markers (Fig. 4).

The barley markers flanking Rps6 showed significant similarity to A. tauschii contigs_6306.1 and 6826.3, designated hereafter as Aet_ctg_6306.1 and Aet_ctg_6826.3. The first sequenced contig (Aet_ctg_6306.1) is $322.7 \mathrm{~kb}$ long and shows significant similarity with proximal barley loci MLOC_52705, MLOC_18254, and Mx_ctg_58199 (Fig. 4). The second sequenced contig (Aet_ctg_6826.3) is $257 \mathrm{~kb}$ long and shows significant similarity with Rps6 linked locus 


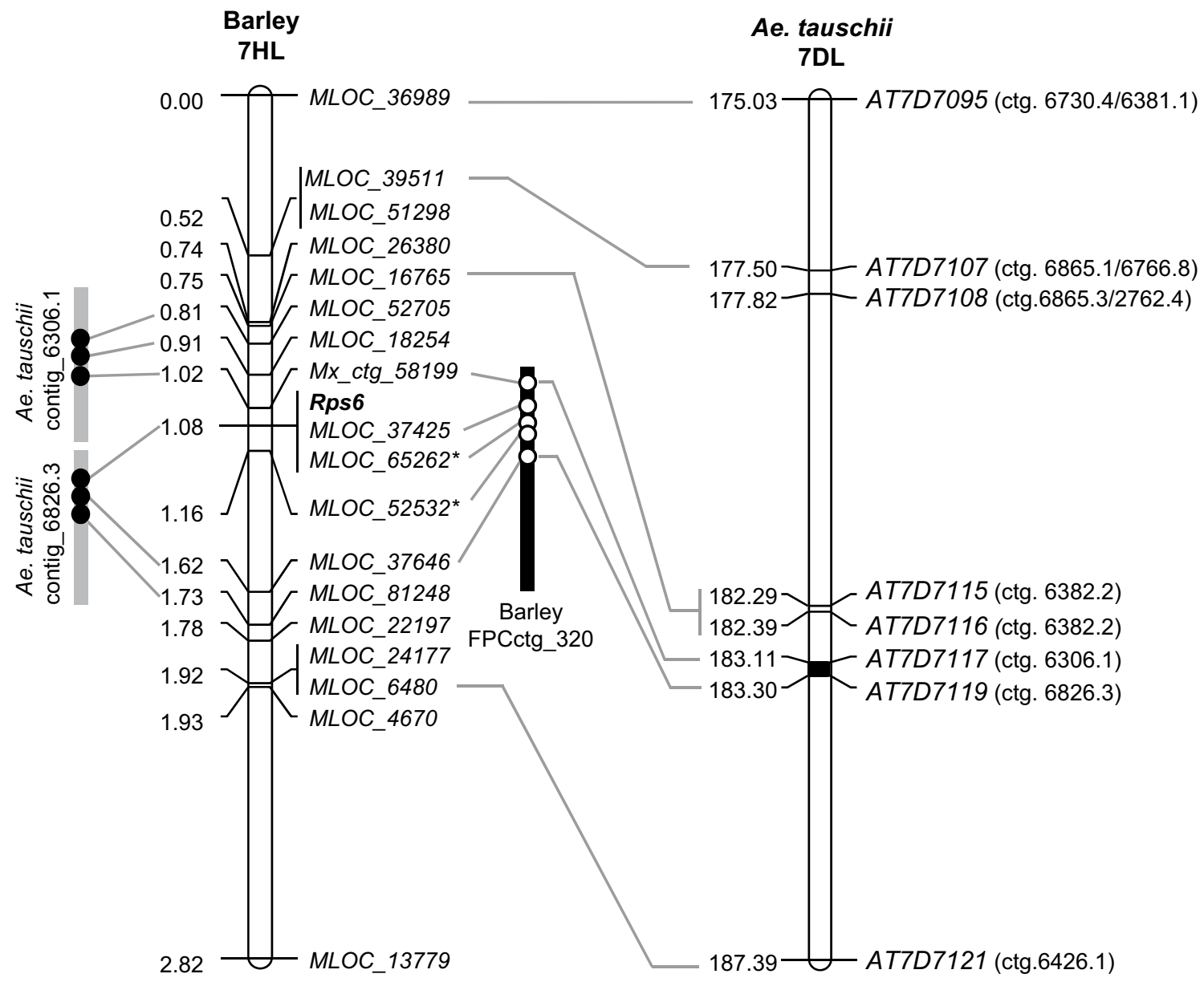

Fig. 4 Comparison between the high-density map of Rps6 in barley chromosome $7 \mathrm{HL}$ and the colinear regions in the genetic map and contig sequences of Aegilops tauschii chromosome 7DL, and the FPC physical maps of barley. The region in black in the genetic maps indi- cates the candidate region for Rps6. The barley and Aegilops tauschii contigs are just schematic representations and are not at scale. Asterisks after MOLC_65262 and MOLC_52532 indicate that these are CC-NBS-LRR genes
Table 4 Brachypodium genes in the region colinear to the Rps6 candidate region

\begin{tabular}{lll}
\hline Gene name in Brachypodium & Barley locus & Predicted function \\
\hline Bradilg30710.1 & MLOC_52705 & Uncharacterized protein \\
Bradilg30700.1 & Not found & Cytochrome P450 71D8-like \\
Bradilg30690.1 & Not found & Uncharacterized protein \\
Bradilg30680.1 & Not found & Uncharacterized protein \\
Bradilg30672.1 & Not found & Zinc finger MYM-type protein 1-like \\
Bradilg30664.1 & Not found & Uncharacterized protein \\
Bradilg30656.1 & $M L O C \_37636^{\mathrm{a}}$ & Methyltransferase chloroplastic-like \\
\hline
\end{tabular}

a Flanking markers outside the Rps6 candidate region
MLOC_37425 and with distal locus MLOC_37646 (Fig. 4). The annotation of the sequences of these two D genome contigs showed no additional genes in Aet_ctg_6306.1, and one additional gene in Aet_ctg_6826.3, which was annotated as a ribonuclease 3-like protein 2 .

\section{Expression of genes linked to Rps6}

Analysis of the expression of MLOC_37425 and MLOC_65262 in leaves (blades and sheaths), roots, and spikes of the variety Golden Promise showed that MLOC_37425 
Fig. 5 Expression profiles of MOLC_65262 and MOLC_37425. The top panel shows expression of the two genes in RNA samples extracted from leaves (blades and sheaths) and roots from Golden Promise plants at the three-leaf stage and from spikes before anthesis. ACTIN was used as endogenous control. The white arrowheads indicate the expected size based on coding sequence. The lower panels are MOLC_65262 and MOLC_37425 RNAseq results for eight tissues from the BARLEX database (Colmsee et al. 2015). Expression levels are presented as fragments per $\mathrm{kb}$ per million reads mapped (FPKM)

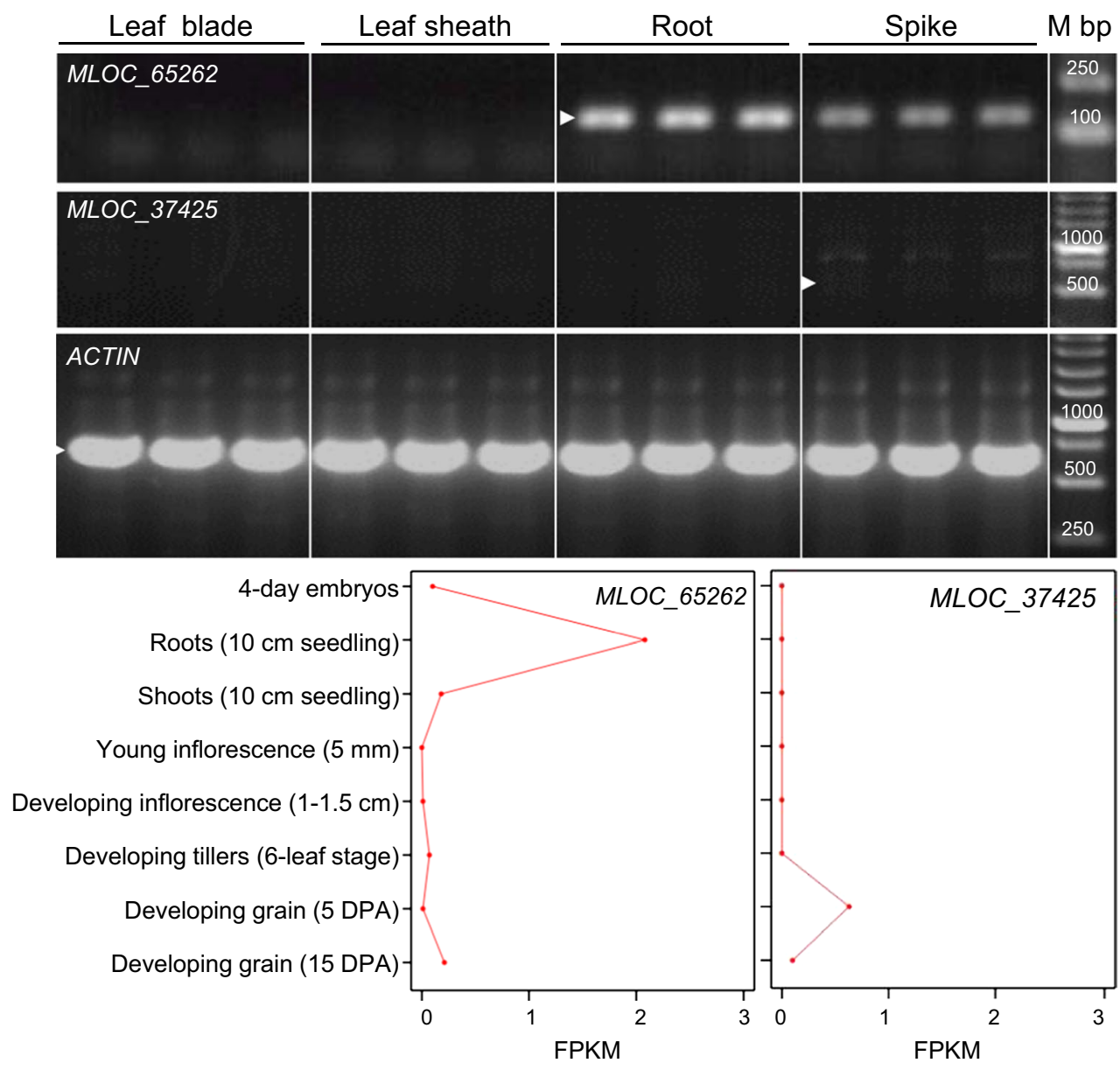

was expressed only in the spikes at very low levels, whereas MLOC_65262 was expressed mainly in roots and spikes (Fig. 5). None of these genes was detected in the RNA samples collected from leaf blades and sheaths. Analysis of RNAseq data for eight tissues available in BARLEX (Colmsee et al. 2015) showed similar expression profiles. $M L O C \_37425$ was not detected in leaves or roots and was expressed at low levels in early grain development. The wheat homolog of MLOC_37425 (Traes_7BL_DA7413B04.1, http://wheat. pw.usda.gov/WheatExp/) was also expressed during spike development and early grain development but not in the leaves (data not shown). In the BARLEX database, MLOC_65262 showed expression in roots but not in leaves (Fig. 5).

\section{Discussion}

\section{Delimitation of the Rps6 candidate gene region in different grass species}

Using orthologs of Rps6 flanking markers we delimited colinear target regions in rice $(<9 \mathrm{~kb})$, Brachypodium (<94 kb), and A. tauschii (0.2 cM, Fig. 4). In the colinear target region in rice chromosome 6 , no additional gene was detected (Fig. 2e). In the colinear target region in Brachypodium chromosome 1, five putative genes were detected, but none of them have barley orthologs on the target sequence of chromosome arm 7HL (Fig. 2d; Table 4). In A. tauschii contig Aet_ctg_6826.3 we found one additional gene similar to barley $M L O C \_81248$, which was annotated as a ribonuclease 3-like protein 2. However, $M L O C \_81248$ was mapped between MLOC_37646 and MLOC_22197, outside the Rps6 candidate region (Fig. 4). The colinear target region in $A$. tauschii was estimated to be less than $0.2 \mathrm{cM}$ long (between 183.1 and $183.3 \mathrm{cM}$ ), and most of the markers were found in two large sequenced contigs (Fig. 4). However, there is still a gap between the two $A$. tauschii contigs in this region, so we cannot rule out the presence of additional genes in the Rps6 colinear regions in this species.

The analysis of the colinear regions in rice, Brachypodium and A. tauschii provided useful information about the similarities and differences among these orthologous regions, but did not identify promising candidate gene for Rps6. Therefore, a dedicated effort in barley will be required to identify Rps6. As a first step to the positional 
cloning of this gene we developed a high-density genetic map and delimited the Rps6 target region to a small genetic interval of $0.14 \mathrm{cM}$, which corresponds to a $\sim 500 \mathrm{~kb}$ region within FPC contig_320 from barley cultivar Morex (Fig. 4).

Once the sequence of this region of chromosome arm $7 \mathrm{HL}$ becomes available, it will be possible to develop additional markers and further dissect the Rps6 target region. We have already identified 15 plants with recombination events between Rps6 and flanking markers Mx_ctg_58199 and MLOC_52532, which can be used to map these additional markers closer to Rps6, narrowing the candidate gene region.

Barley genes MLOC_37425 and MLOC_65262 were mapped completely linked to Rps6 and were considered initially as potential candidate genes. MLOC_37425 encodes a poorly annotated protein that includes a Myblike DNA-binding domain (pfam00249) that is expressed at low levels in the spikes and early grain development (Fig. 5). MLOC_65262 encodes a CC-NBS-LRR resistance gene that was detected only in the roots and spikes. The lack of expression of these two genes in the leaves, where Pst resistance is expressed, suggests that MLOC_37425 and MLOC_65262 are not good candidate genes for Rps6.

It is interesting to mention that flanking marker MLOC_52532 (mapped only $0.08 \mathrm{cM}$ distal to RpsO) is also a CC-NBS-LRR resistance gene (Fig. 2c). Since NBS-LRR genes are frequently present in clusters including multiple resistance genes, we cannot rule out the possibility that additional NBS-LRR genes may be present in the un-sequenced part of the Rps 6 candidate region. In addition, we currently do not known if Rps6 is present in the barley variety Morex. If Rps6 is deleted in Morex, additional studies in barley varieties carrying this gene will be necessary to clone Rps6.

\section{Relationship between Rps6 and other barley resistance genes conferring resistance to different $P$. striiformis formae speciales}

In addition to the Rps6 locus on chromosome arm 7HL, previous studies have identified other barley loci that confer resistance to different $P$. striiformis formae speciales. Pahalawatta and Chen (2005) identified two loci in the barley variety Steptoe that confer resistance to Pst races PST41 and PST-45, and designated them as RpstS1 and rpstS2 (Pahalawatta and Chen 2005). The dominant RpstS1 locus was mapped on chromosome $4 \mathrm{H}$ between resistance gene analog polymorphism (RGAP) markers M1 and M2. The second Pst resistance locus from Steptoe, rpstS2, was not mapped, but its recessive nature suggests that is different from Rps6.

Two other loci conferring resistance to $P$. striiformis $\mathrm{f}$. sp. pseudo-hordei (barley grass yellow rust $=B g y r$ ) have been mapped on the long arm of barley chromosome $7 \mathrm{H}$ (Derevnina et al. 2015; Golegaonkar et al. 2013). The first one, designated as Rpsp-hYerong, confers a dominant resistance to Bgyr isolate 981549 , and was mapped tightly linked to DArT marker $b P b-6167$ (Derevnina et al. 2015). Marker $b P b-6167$ and $R p s 6$ are both located $7 \mathrm{cM}$ proximal to SNP marker 11_1 1012 (Fig. 2), suggesting that Rpsp-hYerong and Rps6 are close to each other. This is also supported by the conclusion of Derevnina et al. (2015) that Rpsp-hYerong is located less than $2 \mathrm{cM}$ from YrpstY1, which was shown in this study to be allelic to Rps6. An allelism test, or a high-density map of Rpsp-hYerong, will be necessary to determine if Rpsp-hYerong is a different gene or if it is allelic to Rps6/YrpstY1. A field study of the Yerong/Franklin double haploid population performed in CIMMYT (Toluca, Mexico) showed that the most significant marker for Bgyr resistance (DArT marker $b P b-6167$ ) was also the most significant marker for resistance to $P s h$. This result suggests that the Rpsp-hYerong locus is associated with resistance to two different $P$. striiformis formae speciales. If future allelism studies confirm that Rpsp$h$ Yerong and Rps6 represent the same locus, this will indicate that the underlying gene is effective against three different $P$. striiformis formae speciales. The broad spectrum of resistance conferred by this gene makes it a valuable target for positional cloning.

An additional recessive seedling resistance locus against Bgyr was detected in the barley variety 'Sahara 3771' and was temporarily designated as rpsSa3771 (=Bgyrl) (Golegaonkar et al. 2013). This locus was mapped on chromosome arm 7HL, $13 \mathrm{cM}$ proximal to marker $w g 420$, which is closely linked to $b P b-6167$ (0.9 cM, Hordeum-Consensus2006-DArT map). Based on these map comparisons, rpsSa3771 seems to map roughly $12 \mathrm{cM}$ proximal to Rps6, suggesting that they are different genes. This hypothesis is also supported by differences in infection reactions to $B g y r$ isolate 981549 (Derevnina et al. 2015) and in the degree of dominance between these two loci. Resistance against this particular isolate is recessive for rpsSa3771 and dominant for Rpsp-hYerong (Derevnina et al. 2015). Rps6 also showed partially dominant resistance to $P s t$ in the experiments described in this study. Taken together, these results suggest that rpsSa3771 and Rps6 are different resistance genes.

\section{Intermediate host resistance}

The previous results indicate that at least three different loci (Rps6, RpstS1 and rpstS2) can contribute to barley intermediate host resistance to Pst. So far, Pst resistance genes RpstS1 and rpstS2 have been reported only in the cultivated barley variety Steptoe. In contrast, Rps6 appears to be more widely distributed, since it was detected in the two Pst resistant wild barley accessions characterized in this study and in the cultivated variety Tamalpais. Based 
on the allelism test with YrpstY1, Rps6 seems to be also present in the Y12 barley accession from China (Sui et al. 2010) and in the cultivated variety Abed Binder 12 reported in the companion study (Dawson et al. 2016). However, we recognize that the number of genetics studies of Pst resistance in barley is still too small to make a valid generalization about the frequency of the different alleles.

In general, wheat stripe rust shows low levels of infection on barley and does not cause significant damage to barley crops. However, if barley resistance to Pst is determined by a limited number of resistance genes, exceptions to this general pattern are expected. Among the $32 \mathrm{H}$. vulgare ssp. spontaneum accessions evaluated in the UCD field in 2010, three showed susceptibility to Pst $(9.4 \%$, Table 1), which was later confirmed in controlled inoculations. The frequency of Pst susceptibility in cultivated barley seems to be lower based on the observation that only a few cultivated barley varieties were reported to be susceptible to Pst. However, a detailed study of six barley varieties from Canada with 38 Pst isolates showed that three varieties were resistant to all $P$ st races, whereas each of the other three, showed susceptibility to 2, 32 and 36 Pst races, respectively (Kumar et al. 2012). This suggests that particular sets of barley accessions may have relatively high frequencies of susceptibility to Pst or that some Pst races are particularly virulent on barley resistance genes. Broader studies including diverse barley germplasm collections and multiple Pst races will be required to answer the previous questions. It will be also interesting to investigate if cultivated barley lines from different geographic origins have similar or different $P$ st resistance genes.

Results from this and previous studies suggest that barley intermediate host resistance to Pst depends in many cases on few major resistance genes, and that the difference between host and intermediate host resistance between wheat and barley may be more tenuous than previously thought. The limited time since the divergence between wheat and barley [ 11 million years (Huang et al. 2002)] might have been insufficient for the development of a more robust nonhost resistance system. As expected, the close evolutionary relation between wheat and barley seems to be also reflected in the relationship between their respective P. striiformis pathogens. A study using Random Amplified Polymorphic DNA markers (RAPD) showed that formae speciales Pst and Psh are more closely related to each other than to $P$. striiformis f. s. poae (Chen et al. 1995). A study using morphological evidence and nuclear rRNA internal transcribed spacer and $\beta$-tubulin sequences also concluded that Pst and Psh were more related to each other than to Puccinia samples collected from species of Poa, Dactylis or Achnatherum (Liu and Hambleton 2010). The initial RAPD (Chen et al. 1995) and isozymes studies (Newton et al. 1985) suggested that $P s t$ and $P s h$ are well differentiated groups. However, the more recent studies based on nuclear
rRNA internal transcribed spacer and $\beta$-tubulin sequences suggest more complex relationships (Liu and Hambleton 2010).

In summary, results from this study suggest that barley resistance to Pst is not effective in all barley accessions and is determined by a simple genetic basis, supporting its classification as intermediate host resistance. These observations also support the hypothesis that effectiveness and genetic complexity of nonhost resistance is correlated with the degree of evolutionary divergence between the host and nonhost plant species (Bettgenhaeuser et al. 2014).

\section{Potential applications of nonhost resistance to crop improvement}

The use of intermediate host resistance genes against $P$. striiformis can benefit both barley and wheat. Barley genes conferring resistance to $P s t$ can be used to improve wheat resistance against Pst, whereas wheat genes conferring resistance to $P s h$ can be used to improve barley resistance to $P s h$. In this study we focused on the precise mapping of the barley Pst resistance locus Rps6 with the longterm objective of cloning this gene and use it as a potential source of Pst resistance for wheat.

This study shows that Rps6 is effective against all Pst races tested so far from China and North America. The resistance to North American race PSTv-51 is particularly important, because this race is virulent to all 18 Pst resistance genes in the wheat differential set, except $\operatorname{Yr} 5$ and Yr15 (Table 3). Race PSTv-51 combines virulences present in previous races PST-114 and PST-127, which represent the two major Pst groups detected in the Western US in recent years (Chen et al. 2010; Wan and Chen 2012). In the companion paper, Rps6 was also shown to be effective against $P$ st races from the UK (Dawson et al. 2016). Rps6 broad spectrum resistance to Pst suggests that this gene may be a valuable tool to control stripe rust in wheat.

Another example of successful use of a nonhost resistance gene among grass species was the transfer of the maize nonhost resistance gene Rxol to rice. Rice plants transformed with this maize gene were resistant against Xanthomonas oryzae pv. oryzae, a pathogen that causes bacterial streak disease in rice (Zhao et al. 2005). A similar transgenic strategy can be used to introgress Rps6 into wheat, once the gene is identified in barley. However, it could also be possible to transfer this gene to wheat by homoeologous recombination, avoiding the costly regulatory processes associated with the release of transgenic commercial varieties. An addition line of chromosome $7 \mathrm{H}$ from barley variety 'Betzes' into wheat cultivar 'Chinese Spring' (Islam et al. 1981), and a spontaneous translocation between chromosome arms 7HL from barley variety 'Manas' and 4BS from wheat variety 'Asakaze Komugi' (Cseh et al. 2011) are available. If Rps6 is present, the 
4BS.7HL translocation would be a better source than the $7 \mathrm{H}$ addition line to transfer the distal region of $7 \mathrm{HL}$ into wheat by homoeologous recombination.

However, the transfer of Rps6 to wheat by homoeologous recombination faces several challenges. The first challenge is the low recombination rate observed between barley and wheat chromosomes even in the absence of the phlb gene (Islam and Shepherd 1992). The second challenge is the potential transfer of undesirable linked traits. It is known that the Phytoene synthase 1 (PSY-1) gene located in the distal end of the long arm of group 7 is associated with the presence of yellow pigments in the flour (Rodriguez-Suarez and Atienza 2012; Zhang and Dubcovsky 2008). If present, this negative effect can be separated from Rps6 by a second round of homoeologous recombination or by mutagenesis, as done before for the PSY-EI gene present in the 7EL translocations from Lophopyrum elongatum (Zhang and Dubcovsky 2008).

The high-density map and the molecular markers developed in this study provide the information and tools required to accelerate the transfer of Rps6 into wheat. If the homoeologous recombination strategy is selected, the markers and maps developed here can be used to monitor and select recombination events close to the Rps6 region. If a transgenic strategy is selected, the two completely linked markers and the closest flanking markers can be used as starting points for the positional cloning of Rps6. The broad resistance conferred by Rps6 to all Pst races tested so far (and possibility to some races of $P$ sh and Bgyr) justifies the effort.

Author contribution statement DF and JD designed the research. KL preformed research and coordinated the experimental part of the project. JH, CZ, AW, JW, GBG, and XC performed research. KL, JH, JD, MMA, and DF analyzed data. KL wrote the first version of the manuscript. All authors reviewed the manuscript. JD provided a major revision of the manuscript and integrated the different contributions.

\footnotetext{
Acknowledgements We thank Qiang Liu and Bo Lv for maintaining the barley populations and Qunqun Hao for help with the expression experiments. We thank Dr. Xianchun Xia for providing the Chinese barley line 'Y12', Dr. J. Dvorak and Dr. M.-C. Luo for his help with the A. tauschii sequences, Dr. T. Close (UC Riverside), and Dr. N. Stein and Martin Mascher (IPK, Getersleben) and the International Barley Genome Sequencing Consortium for their assistance with the barley genomic sequences. We thank Dr. M Moscou for his valuable suggestions during the preparation of this manuscript. Dr. $\mathrm{Fu}$ acknowledges support from the National Natural Science Foundation of China (31110103917), the National Basic Research Program of China (2013CB127700 and 2011CB100700), the Tai'shan Scholar Program of Shandong Province, China, and the Cooperative Innovation Center of Efficient Production with High Annual Yield of Wheat and Corn, Shandong Province, China. Dr. Dubcovsky acknowledges support from the NRI grant 2011-68002-30029 (TCAP) from the USDA National Institute of Food and Agriculture, by the Borlaug
}

Global Rust Initiative, and by the Howard Hughes Medical Institute and the Gordon and Betty Moore Foundation Grant GBMF3031.

\section{Compliance with ethical standards}

Conflict of interests All authors from this study declare that they have no conflict of interests.

Open Access This article is distributed under the terms of the Creative Commons Attribution 4.0 International License (http://creativecommons.org/licenses/by/4.0/), which permits unrestricted use, distribution, and reproduction in any medium, provided you give appropriate credit to the original author(s) and the source, provide a link to the Creative Commons license, and indicate if changes were made.

\section{References}

Abu-Romman SM, Ammari TG, Irshaid LA, Salameh NM, Hasan MK, Hasan HS (2011) Cloning and expression patterns of the HvP5CS gene from barley (Hordeum vulgare). J Food Agric Env 9:279-284

Bettgenhaeuser J, Gilbert B, Ayliffe M, Moscou MJ (2014) Nonhost resistance to rust pathogens-a continuation of continua. Front Plant Sci 5:664

Chen XM, Line RF, Leung H (1995) Virulence and polymorphic DNA relationships of Puccinia striiformis f. sp. hordei to other rusts. Phytopathology 85:1335-1342

Chen XM, Moore M, Milus EA, Long DL, Line RF, Marshall D, Jackson L (2002) Wheat stripe rust epidemics and races of Puccinia striiformis f. sp. tritici in the United States in 2000. Plant Dis 86:39-46

Chen WQ, Wu LR, Liu TG, Xu SC, Jin SL, Peng YL, Wang BT (2009) Race dynamics, diversity, and virulence evolution in Puccinia striiformis f. sp tritici, the causal agent of wheat stripe rust in China from 2003 to 2007. Plant Dis 93:1093-1101

Chen XM, Penman L, Wan AM, Cheng P (2010) Virulence races of Puccinia striiformis f. sp. tritici in 2006 and 2007 and development of wheat stripe rust and distributions, dynamics, and evolutionary relationships of races from 2000 to 2007 in the United States. Can J Plant Pathol 32:315-333

Chen W, Wellings C, Chen XM, Kang Z, Liu T (2014) Wheat stripe (yellow) rust caused by Puccinia striiformis f. sp. tritici. Mol Plant Pathol 15:433-446

Close TJ, Bhat PR, Lonardi S, Wu YH, Rostoks N, Ramsay L, Druka A, Stein N, Svensson JT, Wanamaker S, Bozdag S, Roose ML, Moscou MJ, Chao SAM, Varshney RK, Szucs P, Sato K, Hayes PM, Matthews DE, Kleinhofs A, Muehlbauer GJ, DeYoung J, Marshall DF, Madishetty K, Fenton RD, Condamine P, Graner A, Waugh R (2009) Development and implementation of highthroughput SNP genotyping in barley. BMC Genom 10:582

Collins NC, Thordal-Christensen H, Lipka V, Bau S, Kombrink E, Qiu JL, Huckelhoven R, Stein M, Freialdenhoven A, Somerville SC, Schulze-Lefert P (2003) SNARE-protein-mediated disease resistance at the plant cell wall. Nature 425:973-977

Colmsee C, Beier S, Himmelbach A, Schmutzer T, Stein N, Scholz U, Mascher M (2015) BARLEX - the barley draft genome explorer. Mol Plant 8:964-966

Comadran J, Kilian B, Russell J, Ramsay L, Stein N, Ganal M, Shaw P, Bayer M, Thomas W, Marshall D, Hedley P, Tondelli A, Pecchioni N, Francia E, Korzun V, Walther A, Waugh R (2012) Natural variation in a homolog of Antirrhinum CENTRORADIALIS contributed to spring growth habit and environmental adaptation in cultivated barley. Nat Genet 44:1388-1392

Cseh A, Kruppa K, Molnar I, Rakszegi M, Dolezel J, Molnar-Lang M (2011) Characterization of a new 4BS.7HL wheat-barley 
translocation line using GISH, FISH, and SSR markers and its effect on the beta-glucan content of wheat. Genome 54:795-804

Dawson AM, Ferguson J, Gardiner M, Green P, Hubbard A, Moscou MJ (2016) Isolation and fine mapping of Rps6: an intermediate host resistance gene in barley to wheat stripe rust. Theor Appl Genet. doi:10.1007/s00122-015-2659-x

del Blanco IA, Hegarty J, Gallagher L, Falk BW, Brown-Guedira G, Pellerin E, Dubcovsky J (2014) Mapping of QTL for tolerance to Cereal yellow dwarf virus in two-rowed spring barley. Crop Sci 54:1468-1475

Derevnina L, Zhou M, Singh D, Wellings CR, Park RF (2015) The genetic basis of resistance to barley grass yellow rust (Puccinia striiformis f. sp. pseudo-hordei) in Australian barley cultivars. Theor Appl Genet 128:187-197

Falconer. DS (1964) Introduction to quantitative genetics. Oliver and Boyd Edinburgh

FAOSTAT (2013). Food supply—crops primary equivalent

Golegaonkar PG, Wellings CR, Singh D, Park RF (2013) Genetic and molecular analyses of resistance to a variant of Puccinia striiformis in barley. J Appl Genet 54:1-9

Hovmøller MS, Walter S, Justesen AF (2010) Escalating threat of wheat rusts. Science 329:369

Huang S, Sirikhachornkit A, Su XJ, Faris J, Gill B, Haselkorn R, Gornicki P (2002) Genes encoding plastid acetyl-CoA carboxylase and 3-phosphoglycerate kinase of the Triticum/Aegilops complex and the evolutionary history of polyploid wheat. Proc Natl Acad Sci USA 99:8133-8138

International Barley Genome Sequencing Consortium (2012) A physical, genetic and functional sequence assembly of the barley genome. Nature 491:711-716

Islam AKMR, Shepherd KW (1992) Production of wheat-barley recombinant chromosomes through induced homoeologous pairing. 1. Isolation of recombinants involving barley arms 3HL and 6HL. Theor Appl Genet 83:489-494

Islam AKMR, Shepherd KW, Sparrow DHB (1981) Isolation and characterization of euplasmic wheat-barley chromosome addition lines. Heredity 46:161-174

Johansson ON, Fantozzi E, Fahlberg P, Nilsson AK, Buhot N, Tor M, Andersson MX (2014) Role of the penetration-resistance genes PEN1, PEN2 and PEN3 in the hypersensitive response and racespecific resistance in Arabidopsis thaliana. Plant J 79:466-476

Kumar K, Holtz MD, Xi K, Turkington TK (2012) Virulence of Puccinia striiformis on wheat and barley in central Alberta. Can J Plant Pathol 34:551-561

Line RF, Qayoum A (1992) Virulence, aggressiveness, evolution and distribution of races of Puccinia striiformis (the cause of stripe rust of wheat) in North America, 1968-1987. Technical Volume 1788. United States Department of Agriculture, Washington, $\mathrm{p} 44$

Lipka V, Dittgen J, Bednarek P, Bhat R, Wiermer M, Stein M, Landtag J, Brandt W, Rosahl S, Scheel D, Llorente F, Molina A, Parker J, Somerville S, Schulze-Lefert P (2005) Pre- and postinvasion defenses both contribute to nonhost resistance in Arabidopsis. Science 310:1180-1183

Liu MA, Hambleton S (2010) Taxonomic study of stripe rust, Puccinia striiformis sensu lato, based on molecular and morphological evidence. Fungal Biol-Uk 114:881-899

Luo MC, Gu YQ, You FM, Deal KR, Ma YQ, Hu YQ, Huo NX, Wang Y, Wang JR, Chen SY, Jorgensen CM, Zhang Y, McGuire PE, Pasternak S, Stein JC, Ware D, Kramer M, McCombie WR, Kianian SF, Martis MM, Mayer KFX, Sehgal SK, Li WL, Gill BS, Bevan MW, Simkova H, Dolezel J, Song WN, Lazo GR, Anderson OD, Dvorak J (2013) A 4-gigabase physical map unlocks the structure and evolution of the complex genome of Aegilops tauschii, the wheat D-genome progenitor. Proc Natl Acad Sci USA 110:7940-7945

Muñoz-Amatriaín M, Moscou MJ, Bhat PR, Svensson JT, Bartos J, Suchankova P, Simkova H, Endo TR, Fenton RD, Lonardi S,
Castillo AM, Chao SM, Cistue L, Cuesta-Marcos A, Forrest KL, Hayden MJ, Hayes PM, Horsley RD, Makoto K, Moody D, Sato K, Valles MP, Wulff BBH, Muehlbauer GJ, Dolezel J, Close TJ (2011) An improved consensus linkage map of barley based on flow-sorted chromosomes and single nucleotide polymorphism markers. Plant Genome 4:238-249

Muñoz-Amatriaín M, Lonardi S, Luo MC, Madishetty K, Svensson JT, Moscou MJ, Wanamaker S, Jiang T, Kleinhofs A, Muehlbauer GJ, Wise RP, Stein N, Ma Y, Rodriguez E, Kudrna D, Bhat PR, Chao S, Condamine P, Heinen S, Resnik J, Wing R, Witt HN, Alpert M, Beccuti M, Bozdag S, Cordero F, Mirebrahim H, Ounit R, Wu Y, You F, Zheng J, Šimková H, Doležel J, Grimwood J, Schmutz J, Duma D, Altschmied L, Blake T, Bregitzer P, Cooper L, Dilbirligi M, Falk A, Feiz L, Graner A, Gustafson P, Hayes PM, Lemaux P, Mammadov J, Close TJ (2015) Sequencing of 15,622 gene-bearing BACs clarifies the gene-dense regions of the barley genome. Plant J. doi:10.1111/ tpj. 12959

Newton AC, Caten CE, Johnson R (1985) Variation for isozymes and double-stranded-RNA among isolates of Puccinia striiformis and 2 other cereal rusts. Plant Pathol 34:235-247

Niks R (1987) Nonhost plant species as donors for resistance to pathogens with narrow host range I. Determination of nonhost status. Euphytica 36:841-852

Pahalawatta V, Chen XM (2005) Inheritance and molecular mapping of barley genes conferring resistance to wheat stripe rust. Phytopathology 95:884-889

Rodriguez-Suarez C, Atienza SG (2012) Hordeum chilense genome, a useful tool to investigate the endosperm yellow pigment content in the Triticeae. BMC Plant Biol 12:200

Stein M, Dittgen J, Sanchez-Rodriguez C, Hou BH, Molina A, Schulze-Lefert P, Lipka V, Somerville S (2006) Arabidopsis PEN3/PDR8, an ATP binding cassette transporter, contributes to nonhost resistance to inappropriate pathogens that enter by direct penetration. Plant Cell 18:731-746

Sui X, He Z, Lu Y, Wang Z, Xia X (2010) Molecular mapping of a non-host resistance gene YrpstY1 in barley (Hordeum vulgare $\mathrm{L}$.) for resistance to wheat stripe rust. Hereditas 147:176-182

Wan AM, Chen XM (2012) Virulence, frequency, and distribution of races of Puccinia striiformis $\mathrm{f}$. sp. tritici and P. striiformis $\mathrm{f}$. $\mathrm{sp}$. hordei identified in the United States in 2008 and 2009. Plant Dis 96:67-74

Wan AM, Chen XM (2014) Virulence characterization of Puccinia striiformis f. sp. tritici using a new set of $Y r$ single-gene line differentials in the United States in 2010. Plant Dis 98:1534-1542

Wan A, Zhao Z, Chen X, He Z, Jin S, Jia Q, Yao G, Yang J, Wang B, Li G, Bi Y, Yuan Z (2004) Wheat stripe rust epidemic and virulence of Puccinia striiformis f. sp. tritici in China in 2002. Plant Dis 88:896-904

Wang S, Basten CJ, -B. ZZ (2012) Windows QTL cartographer 2.5 Department of Statistics, North Carolina State University, Raleigh, NC

Wellings CR (2011) Global status of stripe rust: a review of historical and current threats. Euphytica 179:129-141

Yuan CL, Jiang H, Wang HG, Li K, Tang H, Li XB, Fu DL (2012) Distribution, frequency and variation of stripe rust resistance loci Yr10, Lr34/Yr18 and Yr36 in Chinese wheat cultivars. J Genet Genomics 39:587-592

Zhang W, Dubcovsky J (2008) Association between allelic variation at the Phytoene synthase 1 gene and yellow pigment content in the wheat grain. Theor Appl Genet 116:635-645

Zhao BY, Lin XH, Poland J, Trick H, Leach J, Hulbert S (2005) A maize resistance gene functions against bacterial streak disease in rice. Proc Natl Acad Sci USA 102:15383-15388 